\title{
An Experimental Structure and Procedure to Observe Heat Behavior of PV Modules
}

\author{
Ersoy Kelebekler
}

\begin{abstract}
It is well known that open circuit voltage and output voltage decreases significantly while operating temperature of PV cell/module increases. This means reduction of conversion efficiency of cell/module. On the other hand, short circuit current increases slightingly with rise of temperature. In the study, an experimental structure and procedure has been constructed and performed in order to show behavior of $\mathrm{PV}$ cell/module depending on rise of temperature. The proposed experimental procedure is applicable for almost all renewable/alternative energy technology laboratories. Experimental results obtained from the structure for two different illumination values are given on figures and shown how open circuit voltage and short circuit current changes at these illumination values.
\end{abstract}

Index Terms-PV module/cell, heat behavior,

\section{Introduction}

The renewable energy technologies become widespread rapidly in conjunction with increasing energy requirement and they are widely encouraged by many countries, in recent years. Photovoltaic (PV) energy technology convert solar energy into electric energy is one of the most important renewable energy technologies. PV systems can be constructed on most part of the earth, on grid or off grid, on nonmoving or moving subject and also on satellite. Besides, it has very simple/understandable electric connection structure for user need to low power. Flexibility of its applicability holds upper hand against the other renewable technologies.

PV cell, one of the most popular renewable energy products, can directly convert the solar radiation into electricity. Nevertheless, this technology has some disadvantages as the high initial investment cost, the relatively low conversion efficiency of PV cells due to heating of PV panels, dust collection on its surface [1]. During the operation of the PV cell, only around $15 \%$ of solar radiation is converted to electricity and residual energy is converted to heat. The electrical efficiency will decrease when the operating temperature of the PV module increases [2].

In this study, it is aim to design, prepare and perform an experimental mechanism in order to show temperature dependence of solar crystalline silicon PV module for students of vocational high school or university who study on alternative energy technologies.

Ersoy Kelebekler

Kocaeli University

Turkey
The experimental mechanism consists of a monocrystalline silicon PV module, halogen lamps, heat sensors, a current sensor and a data acquisition card. The mechanism is designed to observe and record the short circuit current and the open circuit voltage depending on temperature increment at fixed illumination. The next section includes information and studies on behavior of PV cells/modules depending on temperature. In section 3 , the experimental mechanism is explained broadly. The results obtained from experiments are given and discussed in section 4. The study is ended with conclusion.

\section{Characteristics of PV cells/Modules Depending on Temperature}

Photons can penetrate a semiconducting material and generate charge carriers. One photon absorbed in the region of a $\mathrm{p}-\mathrm{n}$ junction cause to create an electron and a hole. Generation of minority carriers in the $\mathrm{p}-\mathrm{n}$ junction diffusion length diffuse to the depletion layer in which they are carried across by the electrostatic field. The hole of an electron-hole pair generated by a photon on the junction p-type side, remains on the p-type side because the potential barrier at the junction repels the hole, while an electron is impelled toward the n-type side. A similar process happens when the electronhole pairs are generated by light on the junction n-type side [3]. When the solar irradiance increase, the greater number of photons associated with higher solar irradiance creates more electron-hole pairs and consequently more current in the photovoltaic cell and, consequently the PV cell efficiency increase [4]. The density of this conversion process from solar energy to electric energy leads to increase the heat in semiconductor. But this rise also causes to decrease of PV cell efficiency.

PV cell efficiency and output power increase with solar irradiance. While the solar irradiance is higher, more energy is absorbed by the solar module and more heat will be generated [5]. Generally, 80-95\% of absorbed solar energy from solar cells cannot convert to electric energy depending on type of the solar cell. This causes losses and warms up the solar cell simultaneously [6]-[7]. There are many studies in the literature which investigate characterization and efficiency of PV cells depending on temperate change. In these studies, silicon ( $\mathrm{Si}$ ) based technologies categorized as crystalline silicon and amorphous silicon or non-silicon based technologies called also thin film have been examined. Crystalline silicon cells can be also categorized as single/mono crystalline silicon, 
multi/poly crystalline silicon and ribbon cast multi-crystalline silicon [4].

Analytic expressions of output current $I_{L}$, short circuit current $I_{s c}$, open circuit voltage $U_{o c}$, and diffusion voltage $V_{D}$ and their dependence on heat have been given in [3]. In the study, it has been also indicated that lower penetration is obtained as higher temperature and relative sensitivity decreases at higher temperature and short wavelength. As a result of these data, it has been made a decision that temperature as a parameter has a definite influence on the PV conversion in a crystalline solar cell. The output power versus the voltage on the load resistance at the constant illumination at different temperatures have been obtained and given on figures and it shown experimentally in [3] that maximum output power decreases while temperature increases. The effect of the temperature upon the efficiency of various silicon-based PV module types, mono crystalline silicon, multi crystalline silicon and thin flim modules has been investigated by using the Evans-Floschuetz ratio $\left(\eta_{T} / \eta_{\text {ref }}\right)$ in [8] and this ratio has been plotted against the operating temperature in [4] and [8]. Where $\eta_{T}$ is cell/module electrical efficiency at related temperature and $\eta_{\text {ref }}$ is cell/module electrical efficiency at reference condition temperature. The results presented in these studies can be summarized as follow. The effect of temperature for mono crystalline silicon modules is larger for all values of temperature between $300 \mathrm{~K}$ and $300 \mathrm{~K}$. Nevertheless the effect of temperature for the thin film modules is fewer for the temperatures. The decrease in the efficiency of mono crystalline silicon cells and thin film cells are observed to be about $15 \%$ and $5 \%$, respectively, as the module temperature rises from $300 \mathrm{~K}$ to $330 \mathrm{~K}$. It has been stated in [4] that A cooling mechanism is required for the mono and poly crystalline silicon PV modules, which are the most affected PV types by module temperature, in order to sustain efficiency at high temperatures. Because they have the biggest market share which are $42.2 \%$ for the mono crystalline silicon and $45.2 \%$ for poly crystalline silicon by year 2011 .

In different studies, the temperature effect on PV cell performance of different types has been studied and shown its negative effect on conversion from solar energy into electric energy. Decrement of PV cell/module electrical efficiency versus temperature increment has been report in some of these studies. Different temperature dependences for PV performance have been reported and it has been found in [9] that the efficiency of crystalline silicon cells drops at a rate of around $0.45 \% /{ }^{\circ} \mathrm{C}$. It is also stated in [9] that crystal silicon cells are still dominant in market and their performance are heavily affected by high cell temperature and the effect of temperature draws a great deal of research attention since relative high cell temperature during cell operation contributes to short-term efficiency loss as well as long-term irreversible cell degradation. Reduction of the photoelectric conversion efficiency has been presented as $0.2 \%-0.5 \%$ against PV operating temperature increase of $1 \mathrm{~K}$ for solar cells in [10]. The variation of energy conversion efficiency with temperature has been given for crystalline silicon or thin film in [11]. The electrical conversion efficiency for a crystalline silicon module decreases by $0.5 \%$ for every $1{ }^{\circ} \mathrm{C}$ increase in the module operating temperature. Nonetheless, thin film type has lower negative temperature coefficient compared to crystalline silicon. For thin film technology, the drop in efficiency of PV modules made of amorphous silicon (a-Si), cadmium telluride (CdTe) and copper indium gallium selenide (CIGS) is in the order of $0.21,0.25$ and $0.32-0.36 \%$ per ${ }^{\circ} \mathrm{C}$ rise in module temperature [11], [12].

It is well known as presented above that the PV electrical efficiency decreases with increment of temperature. Actually this decrement is observed on output voltage and fill factor. With an increase in the PV cell temperature, the open circuit voltage and fill factor is reduced, which decreases the conversion efficiency of the PV system [13]. It has been observed in experimental tests and practical applications that the voltage of $\mathrm{PV}$ modules $\left(V_{p v}\right)$ decreases linearly with an increase in the ambient temperature and satisfies the following equation [14]:

$$
V_{p v}=V_{p v 0}+C_{T} T_{a}
$$

Where, $V_{p v 0}$ is the intercept of voltage of PV modules at $T_{a}$ $0{ }^{\circ} \mathrm{C}, C_{T}$ is the temperature coefficient of PV module's voltage and is a negative value $\left(\mathrm{V}{ }^{\circ} \mathrm{C}^{-1}\right)$ and $T_{a}$ is the ambient temperature. In the study [4], it has been also stated that PV efficiency decreases as PV temperature increases, mainly because a higher cell temperature decreases the voltage significantly. Nevertheless, increment of cell temperature increases the current by a very small amount. The increment of output current depending on temperature rise is shown experimentally in [14], [15]. It has been also indicated in [15] that the increase in operating temperature of the PV cells for mono and polycrystalline PV cells increases in short circuit current $\left(I_{s c}\right)$ of $0.06-0.1 \% /{ }^{\circ} \mathrm{C}$. Besides, the reason for this increment has been explained in [14] as the exponential dependence of the saturation current $\left(I_{s a t}\right)$ on the temperature so that short circuit current increases slightly.

\section{Experimental Structure}

The target group of the study is students studying alternative energy technologies. Number of education programs of alternative energy technologies and the students studying in these programs are going up in parallel with rise of energy requirement, variety and fields of application. The heat behavior of PV cells/module is given theoretically the students in the schools. However this behavior is not usually studied experimentally. The experimental mechanism prepared in the study is constructed to show how the short circuit current and the open circuit voltage change as operating temperature increasing. The experimental mechanism consists of $20 \mathrm{~W}$ monocrystalline silicon PV module, $3 \times 500 \mathrm{~W}$ halogen lamps, 8 heat sensors, a current sensor and a data acquisition card.

PV modules used on solar experimental sets designed for alternative energy laboratories usually include mono or poly crystalline solar cells. Because their output power and electrical conversion efficiency is higher than amorphous silicon thin film or non-silicon based thin film. On the other hand, the temperate sensitivity of these PV cells is greater than the others [4], [8]-[9], [11],[12]. In the experiment structure is 
Proc. of the Fourth International Conference on Advances in Mechanical and Robotics Engineering - AMRE 2016.

Copyright $\odot$ Institute of Research Engineers and Doctors. All rights reserved.

ISBN: 978-1-63248-115-3 doi: 10.15224/ 978-1-63248-115-3-34

used 20W monocrystalline silicon PV module with $21.5 \mathrm{~V}$ open circuit voltage, $1.24 \mathrm{~A}$ short circuit current, 17.2 maximum power voltage and $1.15 \mathrm{~A}$ maximum power current. Eight LM35 precision centigrade temperature sensors whose front sides were covered with heat transfer compound were adhered back side of the PV module as shown Figure 1.

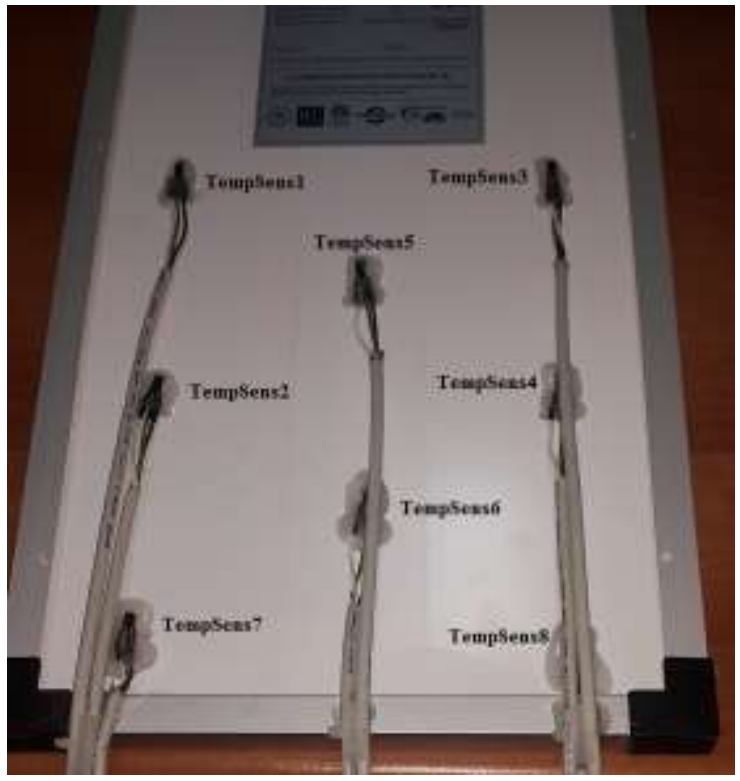

Figure 1. Back side of PV module and positions of the sensors

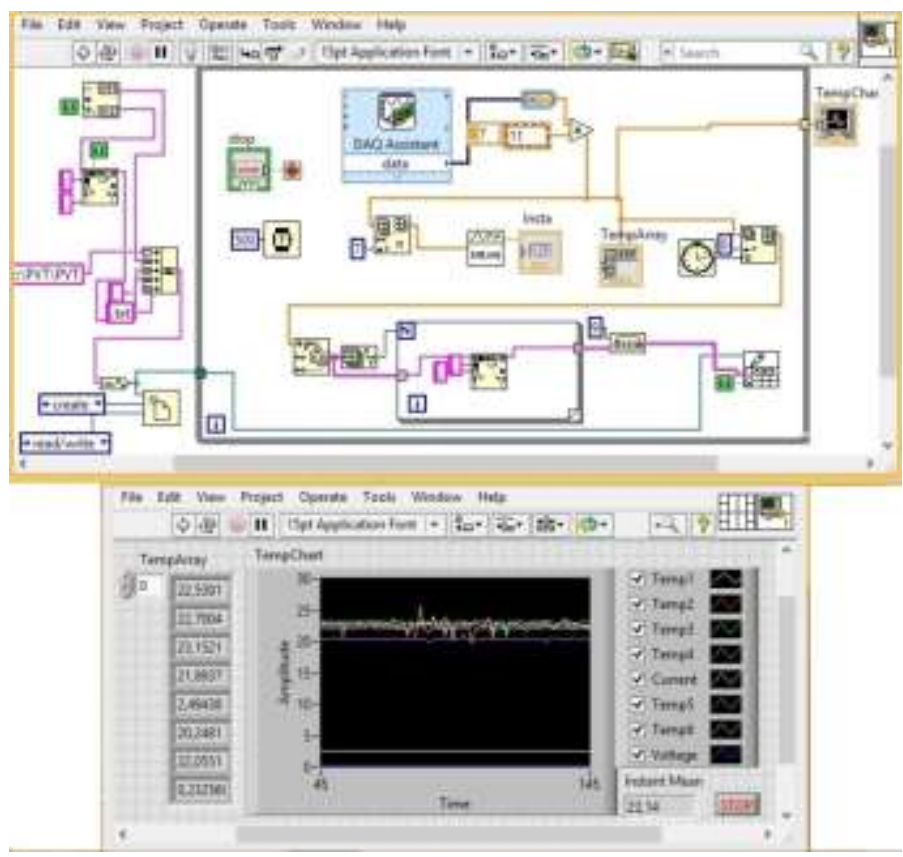

Figure 2. Interface of the software

Three halogen lamps with $500 \mathrm{~W}$ power were used for illumination on experiment structure. ACS714 hall effectbased linear current sensor was used to measure the short circuit current at fixed illumination values. National Instrument NI USB-6002 data acquisition card acquires the data as temperate, current and voltage and the software prepared on Labview records them computer. The interface of prepared software is given in Figure 2.

NI 6002 DAQ has 8 analog input channels. Six of them were connected to temperature sensors and the others were used for the current sensor and voltage. The sensors from number 1 to number 6 displayed in Figure 1. were utilized at experimental applications.

\section{Experimental Results and Discussions}

Experimental structure is given in Figure 3. The experiments were performed at two illumination values which were supplied by taking the distance between PV module and halogen lamps, $51 \mathrm{~cm}$ and $16 \mathrm{~cm}$, respectively. The experiment comprises of two stages. Firstly, the open circuit voltage and temperatures taken from six sensors were recorded at fixed illumination. In this process, the voltage value and the temperature values were also observed on user interface of the software. After the module was gotten cold, in the second stage, the short circuit current and temperatures acquired from six temperature sensors and current sensor were recorded at the same illumination. Obtained data at first illumination were transferred graphical display. This process was repeated at second illumination for the study.

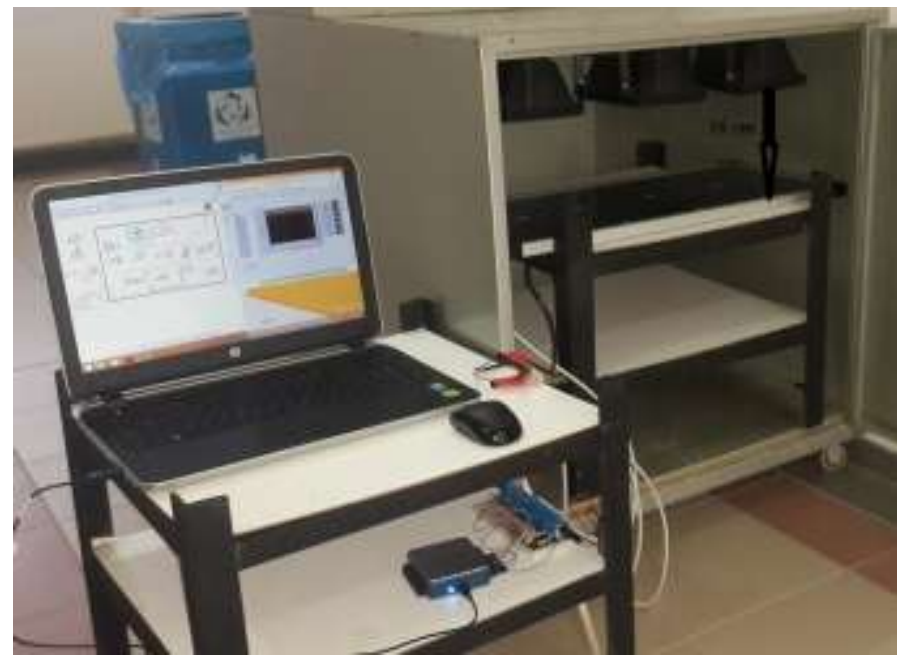

Figure 3. Experimental Structure

The results obtained from experiments for first illumination value by taking the distance $51 \mathrm{~cm}$ is given Figure 4. The left vertical axis scales temperature values and the right side scales open circuit voltage and short circuit current, together. Data acquisitions were started at $25.5{ }^{\circ} \mathrm{C}$ (mean of the sensor temperatures) for each of $I_{s c}$ and $V_{o c}$ and data were recorded during 25 minutes as shown Figure 4. Open circuit voltage drops from $19.18 \mathrm{~V}$ to $16.82 \mathrm{~V}$, while short circuit current increases from 0.534 A to 0.579 A during the duration when the mean of the temperatures increases from $25.5{ }^{\circ} \mathrm{C}$ to $52.66{ }^{\circ} \mathrm{C}$. 


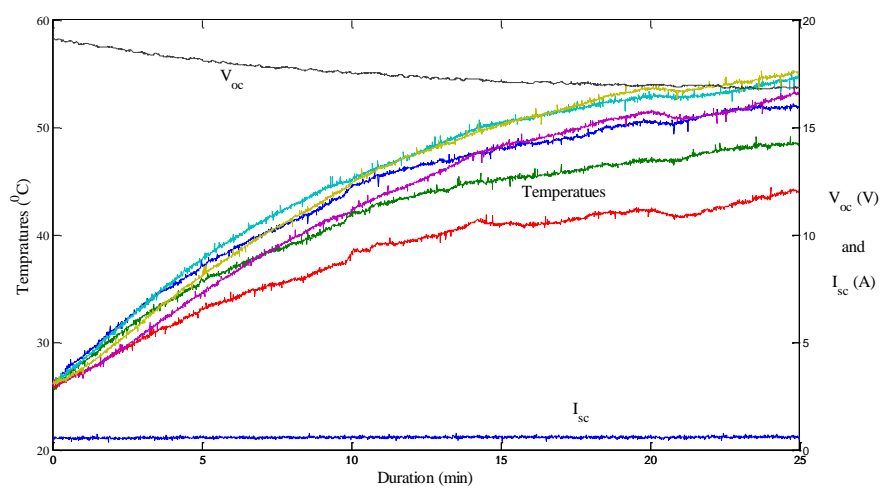

Figure 4. The experimental results for the first illumination obtained at the distance $51 \mathrm{~cm}$

In Figure 5. it is given the experimental results obtained for the second illumination at the distance $16 \mathrm{~cm}$. At this distance, the PV module warms quicker and mean of temperate arrives over a hundred degree in fifteen minutes. The experiment was started at $22{ }^{\circ} \mathrm{C}$ for each of $I_{s c}$ and $V_{o c}$. The open circuit voltage starts $20.39 \mathrm{~V}$ and drops $15.32 \mathrm{~V}$, end of the 12 minutes. This drop can be seen easily in the figure. Value of the short circuit current is $0.789 \mathrm{~A}$ at the beginning and it arrives to $0.888 \mathrm{~A}$ end of this duration. This increment is given obviously in the second axis inserted in Figure 5.

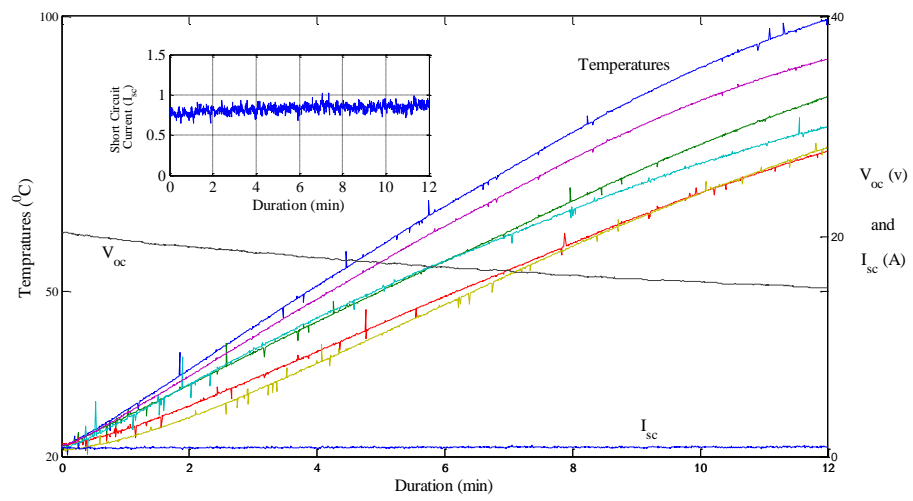

Figure 5. The experimental results for the second illumination obtained at the distance $16 \mathrm{~cm}$

\section{v. Conclusion}

An experimental structure and procedure is aimed to show the behavior of PV module depending on temperature for the students studying on programs of renewable energy source. The experimental structure consists of a monocrystalline silicon PV module with $20 \mathrm{~W}$, three halogen lamps with $500 \mathrm{~W}$, heat sensors, a current sensor and a NI 6002 data acquisition card. The heat sensors were adhered back side of the PV module and six of them connected to inputs of the data acquisition card. Additionally, it is possible to watch and record changing of temperatures and open circuit voltage and short circuit current with prepared software.

The experimental procedure comprise of two stages. At a fixed illumination, it is measured and recorded one of open circuit voltage or short circuit current by the system. Later, the other is measured at the same illumination after the PV module is gotten cold. The experimental results shows that the open circuit voltage drops dramatically and the short circuit current increases small amount as reported in the literature. The experimental procedure provides the student to see behavior of PV module depending on temperature.

Duration passing from beginning to end of the experiment is the most important disadvantage of the experiment procedure. Nevertheless, the proposed experimental procedure can be used for all kind of PV module type. Besides, the experimental procedure can be carried out almost whole renewable/alternative energy technology laboratories which has PV cell or module and two multimeter, one of them has ability to measure temperature. The thermocouple of multimeter can be adhered similarly back side of the PV module and the other multimeter can be used to measure open circuit voltage and short circuit current. The experimental procedure, recording temperature and voltage or current as changing temperature, can be followed by students at a fixed illumination value.

\section{References}

[1] Bahaidarah H, Subhan A, Gandhidasan P, Rehman S. Performance evaluation of a PV(photovoltaic) modüle by back surface water cooling for hot climatic conditions. Energy, vol. 59, pp. 445-53, 2013.

[2] H.G.Teo, P.S.Lee, and M.N.A.Hawlader, "An active cooling system for photovoltaic modules," Appl. Energy,vol.90,no.1,pp.309-315,Feb.2012.

[3] Radziemska E. The effect of temperature on the power drop in crystalline solar cells. Renew Energy, vol. 28, no. 1, pp. 1-12, 2003.

[4] Kumar R, Rosen M. A. A critical review of photovoltaic-thermal solar collectors for air heating. Appl Energy, vol. 88, no. 11, pp. 3603-3614, 2011.

[5] Amin N, Lung C W, Sopian K. A practical field study of various solar cells on their performance in Malaysia. Renew Energy, vol. 34, no. 8, pp. 1939-1946, 2009.

[6] Ji Jie, Jian-Ping Lu, Tin-Tai Chow, Wei He, Gang Pei, A sensitivity study of a hybrid photovoltaic/thermal water-heating system with natural circulation, vol. 84, no. 2, pp. 222-237, 2007.

[7] Erdil E, IlkanM, EgeliogluF. An experimental study on energy generation with a photovoltaic(PV)-solar thermal hybrid system. Energy, vol. 33, no. 8, pp. 1241-1245, 2008.

[8] Skoplaki E, Palyvos JA. On the temperature dependence of photovoltaic module electrical performance: a review of efficiency/power correlations. Solar Energy, vol. 83, 614-624, 2009.

[9] Du D, Darkwa J, Kokogiannakis G. Thermal management systems for photovoltaics(PV) installations: a critical review. Sol. Energy, vol. 97, pp. 238-54, 2013.

[10] X. Tang, Z. Quan and Y. Zhao, "Experimental Investigation of Solar Panel Cooling by a Novel Micro Heat Pipe Array," Energy and Power Engineering, vol. 2 no. 3, pp. 171-174, 2010.

[11] Chandrasekar, M. \& Senthilkumar T., Passive thermal regulation of flat PV modules by coupling the mechanisms of evaporative and fin cooling, Heat Mass Transfer, vol. 52, pp. 1381, 2016. 
[12] Radziemska E, Klugmann E, Thermally affected parameters of the current-voltage characteristics of silicon photocell. Energy Convers Manag, vol. 43, pp.1889-1900, 2002.

[13] Baloch AAB, Bahaidarah HMS, Gandhidasan P, Al-Sulaiman FA. Experimental and numerical performance analysis of a converging channel heat exchanger for PV cooling. Energy Convers Manag., vol. 103, pp. 14-27, 2015.

[14] Jiang J-A, Wang J-C, Kuo K-C, Su Y-L, Shieh J-C, Chou J-J. Analysis of the junction temperature and thermal characteristics of photovoltaic modules under various operation conditions. Energy;vol. 44, no. 1, pp. 292-301, 2012.

[15] S. Sargunanathana, A. Elangob, S. Tharves Mohideenc, Performance enhancement of solar photovoltaic cells using effective cooling methods: A review, Renewable and Sustainable Energy Reviews, vol. 64, pp. 382-393, 2016,

About Author:

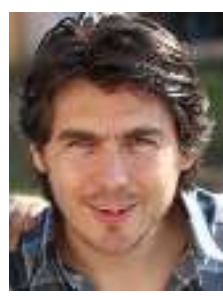

Ersoy Kelebekler was born in Bursa, Turkey in 1980. He received the B.S. and M.S. degrees in department of electronics and computer education from Kocaeli university, in 2002 and 2006 , respectively. He is currently working on his Ph.D.thesis at the department of electronics and computer education of Kocaeli university. His research interests are in renewable energy source, computer-aided analysis of active and passive circuits and theoretical electromagnetics. 